ARTICLE

DOI: $10.1057 /$ s41599-018-0195-4

\title{
The AMR problem: demanding economies, biological margins, and co-producing alternative strategies
}

\author{
Steve Hinchliffe (iD ${ }^{1}$, Andrea Butcher (iD ${ }^{1}$ \& Muhammad Meezanur Rahman (D) ${ }^{2}$
}

\begin{abstract}
Widespread antimicrobial resistance (AMR) poses a threat to public and animal health, and has consequences for the structure and sustainability of food production. The problem is often framed as one of inappropriate antimicrobial use, which drives emergence and selection of resistant microbes. The answer to this framing of the problem is to lower disease incidence and transmission rates, regulate antimicrobial uses and to educate prescribers and users of medicines. In this paper we argue that this seemingly straightforward programme of action is beset by at least two difficulties. First, in many parts of the world, disease dynamics and antimicrobial uses are embedded within biosocially demanding settings. Second, antibiotic use is one among many possible drivers of resistance. We focus on the aquatic environment and aquacultural food production where resistance drivers may relate to a variety of processes. Using interviews, survey data, and participatory modelling exercises with competency groups in Bangladesh's shrimp and prawn aquaculture sector, we demonstrate the need to understand economic and biological drivers of disease, farmer adaptations to disease risks and the potential paradox of pursuing pathogen-free food production as a means to reduce AMR risks. We argue that the AMR problem needs to be framed as an adaptive rather than technical challenge, and involves ownership, change and experimentation across a range of relevant sites.
\end{abstract}

\footnotetext{
${ }^{1}$ Geography, College of Life and Environmental Sciences, University of Exeter, Exeter, UK. ${ }^{2}$ WorldFish, and CGIAR research program FISH, Dhaka 1213, Bangladesh. Correspondence and requests for materials should be addressed to S.H. (email: Stephen.hinchliffe@exeter.ac.uk)
} 


\section{Introduction}

- he emergence, persistence and transmission of microbes that are resistant to available medicines constitute a major threat to medical practice and public health. In the main, antimicrobial resistance (AMR) has been framed as a matter of people making ill-informed choices, culminating in over- and irrational use of antimicrobial medicines (Leung et al. 2011, Laxminarayan et al. 2013). The resulting surfeit of antimicrobial compounds in bodies, clinics, communities, food systems and environments produces the conditions for selection of microbes that are resistant to the currently limited set of available treatments. The paradigm is a commons problem, fanned by a mismatch between private benefit and public cost (Lee and Motzkau, 2013). The solution, if we follow this formatting of the problem, is to reduce inappropriate and so-called irrational antimicrobial uses by providing improved information, shifting the incentives that drive people to act in non-ideal ways, regulating medicine use and so changing treatment choices and behaviours. This framing is common across various health care sectors, and is becoming particularly prominent in the morally-charged food and livestock sector, where a majority of the world's antimicrobials are currently consumed (Van Boeckel et al. 2015).

Focussing on AMR as it relates to livestock farming (and more specifically aquaculture, currently the fastest growing food production sector (FAO, 2018: 114)), we make two interrelated points in order to offer an alternative problematisation and way forward. First, for a growing group of scientists, the emergence, persistence and transmission of antimicrobial resistance may relate to a host of drivers or ecologies and are not reducible to medicine use alone. Second, drawing on our fieldwork, we describe how AMR risks, disease and disease treatments relate to social ecologies of food production. Only by understanding those ecologies and by working with key actors can we co-develop pathways to reducing the burden of AMR.

We take an approach informed by a need to understand the AMR problem as an adaptive challenge (Heifetz, 1994). That is, change and experimentation are required across multiple sites in ways that are consistent with the starting conditions within those sites. And, as a means to recognise the heterogeneity of and linkages between settings, we understand the AMR problem as a matter of actor networks, or the continuous assemblage of network elements in ways that can generate change (Callon, 1986, Law, 2006). Our empirical focus is food production, and more specifically the production of shrimp and prawn in Bangladesh. Our approach is multi-sited and grounded in particular practices. We use a suite of methods as a means to elicit expertise and experiences of those most familiar with the issues at hand. Survey and qualitative interviews are combined with reflections on the competency groups (collectives of various experts including farmers, scientists and officials (Whatmore, 2009, Whatmore and Landstrom, 2011)) that we staged in order to generate participatory knowledge and heuristic models of disease and resistance risks. In the latter, we aimed to work together with farmers and other experts in order to identify key drivers of disease, treatment uses, resistance risks and adaptive changes to production. In working through these sites and methods our intention is to shift the focus for social science work on AMR and to demonstrate a situated understanding of human-microbe interactions.

After setting out the background to the problem of AMR, we move to the shrimp and prawn hatcheries of southwest and southeast Bangladesh where workers and broodstock (gravid mothers) struggle against economic and biological margins (including disease) to make enough viable seed to supply the large number of mostly small scale grow-out farms in south west Bangladesh. From the hatcheries, seed are transported to various markets and on to farms where these minute crustaceans and their microbial co-travellers are added to ponds. The tens of thousands of ponds are the growing medium for shrimp, prawn, sometimes rice, often finfish, snails and others besides (including of course many micro-organisms, both beneficial and otherwise). They have also been sites of relatively recent struggles over property, labour, ecology and land use, salinisation, as well as being subject to flooding, uncertain monsoon and climate (Jalais, 2011, Islam, 2014). The produce from the myriad of ponds is collected by processors and exporters and this, coupled with the risks of small farm production on a fertile yet precarious landscape, lends this supply chain the characteristics of what Tsing (2015) has called 'salvage accumulation' (where lead firms amass capital without controlling the conditions under which commodities are produced). As is the case for the hatcheries, securing livelihood from these ponds is a matter of working the margins. We detail the relevance of these margins and this mode of accumulation in terms of the biosocial nature of disease and resistance risks (Farmer, 2004, Farmer et al. 2006, Hinchliffe et al. 2016). We introduce the term 'sociobiome' to underscore the interrelationships between social and biological processes that shape the health of a food production system and seek to demonstrate its relevance to a re-considered approach to AMR.

\section{Framing the AMR problem}

Over the course of the last 70 years, the selective targeting and suppression of microbial forms of life have become mundane technologies in human and animal health care and in food production. From the modified brewing industry vats in the Midwest of the United States that were used to industrially manufacture antibiotics derived from soil bacteria in the 1940s (Landecker, 2016), to the globalised production and distribution of synthesised pharmaceutical components in India, China and elsewhere, antimicrobials are produced and consumed in mass. In human medicine, global use is in the order of 70 Billion standard units (an SU is a measure of volume based broadly on the smallest identifiable dose given to a patient) (Van Boeckel et al. 2014). In agriculture, livestock consumes around 60,000-70,000 tons of antibiotics every year (though this may be a considerable underestimate of total use). This figure likely exceeds direct human consumption, and is projected to increase significantly over the next few decades as demand for animal protein expands and livestock rearing practices intensify (Van Boeckel et al. 2015). This material history and the ramifications of a mass of antimicrobials and resistance-conferring compounds and genes contribute to a new planetary biology (Landecker, 2016). Selection pressures, the emergence of resistant microbes and the lateral transfer of mobile genetic elements within complex 'multi-species' (or post-species) populations of micro-organisms have generated shifts in the pangenome (the core and accessory genes that are available to microbial populations) (Gillings, 2017). The short to medium term results, in terms of the effectiveness of available medicines and the prognoses for human health care, are now well-known (Davies, 2013).

A key response to the emerging crisis has been to seek to reduce unnecessary uses of medicines, especially those that are deemed critical for human health. This seemingly uncontroversial attempt to sustain the efficiency of existing therapeutics is embedded in World Health Organisation-sponsored National Action Plans and research-funding calls, many of which have adopted the language of 'stewardship' (World Health Organisation, 2015). This formatting of the antibiosis problem has simultaneously drawn upon and nurtured a particular paradigm or approach to social science research and intervention. As medicine use is rendered as inefficient or irrational, and as the 
issue is framed as one of expert knowledge versus inexpert practices, then the 'lever' for change almost always becomes the behaviour of those demanding or administering medicines in ways that are sub-optimal. Social science is positioned as a means to account for the persistence of 'incorrect' knowledge and behaviour, and, in tandem with public health, a toolkit for raising awareness and targeting inappropriate uses. There is an accompanying tendency to focus on individual behaviours with minimal consideration of the socially and economically embedded nature of action, and to assume that models of behaviour honed in higher income settings are applicable elsewhere. In the context of a global health challenge, social science is thus rendered as a form of 'first world' expertise. The deracinated result is a colonial "onesize-fits-all approach, framed with developed country contexts in mind" (Kakkar et al. 2018). In essence, as antibiotic use becomes the driver or determinant of resistance and the target of intervention, other possible resistance risks, as well as the social and economic conditions of antimicrobial use (including food security, poverty alleviation, healthcare access and so on) tend to be ignored (Kakkar et al. 2018). The result can be both ineffective and wasteful.

The role of antimicrobial compounds as key drivers of resistance is of course well-founded on good laboratory understanding of the key molecular mechanisms through which resistance can be conferred (including cell membrane changes, intracellular modifications, extrusion processes, sensitivity reductions and sequestration of active agents) (Holmes et al. 2016). These mechanisms can be acquired by mutation or through horizontal gene transfer between strains of bacteria. Many are associated with fitness costs, so it is often assumed that resistant strains require continuous suppression of antimicrobial susceptible bacteria in order to flourish. Continuous inappropriate use of antimicrobial medicines and treatments would of course provide that selective gradient.

Despite this apparent simplicity, the detailed processes though which resistance traits emerge, persist, expand and then spread are less well characterised (Bengtsson-Palme et al. 2018). In part they relate to the varied ecologies within which microbes evolve and transmit resistance to one another, and so include an array of environmental variables: for example presence of heavy metals and detergents can modulate gene transcription; biofilms (an assemblage of microorganisms embedded in an extracellular matrix that adhere to themselves and to surfaces) can harbour diverse microbial populations and act as long-term reservoirs for antimicrobial resistance genes (Taylor et al. 2011). Others have demonstrated that qualitatively different pathways to resistance, involving selection for different sets of resistance conferring genes, can occur at very low drug concentrations (Bottery et al. 2016, Wistrand-Yuen et al. 2018). The implication is that "even weak selective pressures can cause evolution of high-level resistance" (Wistrand-Yuen et al. 2018).

The aquatic environment is not unique but is possibly critical in respect of these environmental and microbial dynamics. The following features make these environments and aquacultural food production potentially important in terms of emergence, persistence and transmission of AMR (Taylor et al. 2011). Inland water bodies and coastal zones have high and diverse bacterial loads, and often act as sinks for treated and untreated waste, agricultural runoff and pollution. Sediments and biofilms act as media for the adsorption and maintenance of microbes and resistance conferring materials. In terms of aquacultural food production, inputs of detergents and therapeutants can modify resistance factors, while water exchange from and to surrounding environments can aid transmission. Stocking may be dense, with animals that are subject to a variety of stressors and diseases. Zooplankton and filter feeders may serve to concentrate pathogen populations and or heavy metals or other resistance factors. Finally, the mixing of the medium, its transport and its importance to human well-being (in terms of drinking, washing and other activities) make this a potentially important gateway for cross-species transmission (Cabello et al. 2016). Needless to say, an industry within which there are movements of stock, water exchanges and complex food distribution networks lends a more variegated structure to this potential set of human-animal-microbe interactions. These are all, it should be noted, social as well ecological matters. The state of a microbial environment, its dynamics and its interactions with other environments are effects of and affect economic and social lives. In our terms, they are entangled within and inseparable to ecologies of production.

The point of this list is not to be comprehensive. It is to emphasise, first, that AMR will relate to, but is not straightforwardly determined by, on site use of treatments. Relatively small amounts of use, or uses elsewhere (for example in terrestrial agriculture), may have important effects on the emergence and spread of resistance within the aquatic environment. Second, the scope and importance of the kinds of social science that are relevant to the AMR problem are as such broadened from a narrow focus on governing medicine use. Alongside the social and economic drivers of disease, and disease control, are the interrelationships between people, environments and microbes. Here we would emphasise the point that people, like other actors in the resistance landscape, are embedded within relations that shape their activity levels and their ability to make significant change. Agents or actors, be they resistant bacteria or people, emerge in networks or situations (Hinchliffe et al. 2016). Only by understanding people, microbes, fish, and so on as situated beings, can we appreciate the ways in which the AMR problem arises. Similarly, only by appreciating the problem can we hope to develop appropriate ways forward.

These basic tenets of a relational, or actor-network approach (Law and Hassard, 1999), require field working styles that can work with social and material complexities and identify key relations (Law, 2004). It is with those aims in mind that, following a brief note on methodology, we work through interrelated field sites as a means to distil the key relationships that contribute to the AMR problem.

The multi-sited and multi-factorial nature of adaptive challenges requires a range of field approaches, drawing most obviously on multi-sited approaches to field working and ethnography (Marcus, 1995). But beyond the close and situated work of ethnography, an adaptive challenge requires field breadth. Our methods therefore included longer interviews and field observations at hatcheries, on farms and in supply shops, a structured survey of hatcheries $(n=26)$ and shrimp and prawn farms $(n=$ 320 ) and the formation of competency groups to map key pathways and relations that contribute to disease and resistance risks within the sector. For the purposes of this paper, analysis of the field materials generated was largely qualitative, drawing out broad trends and characteristics from the surveys rather than reporting on the quantitative analysis undertaken elsewhere in the project. In that sense we have not focused on statistically significant causal relationships between variables within our data. Rather, the approach has been to develop accounts of practice through, for example, descriptive statistical representations of survey results and narrating themes that emerged across our entire data corpus. The latter developed from close reading of field and interview notes with farming and other experts and discussion within the research team concerning how best to interpret field results. 


\section{Economic and biological margins at the hatcheries}

Just south of Cox's Bazar, on the coastline of the Bay of Bengal, and far to the south of the sediment rich flood plains that characterise much of Bangladesh's land area, there are around 60 tiger shrimp (Penaeus monodon) hatcheries, most of which were built in the 1980s and 1990s with substantial support from development banks. Some of them lie dormant, but 30 or so currently attempt to produce postlarvae (hereafter PL). These hair-like juvenile shrimps are destined for grow out ponds, most of which are located in southwest Bangladesh, roughly $700 \mathrm{~km}$ away (see Fig. 1).

The hatcheries are in Cox's Bazar for several reasons. To successfully culture enough PL they need plentiful supplies of clear and clean water. Unlike the turbid river waters to the north and west, the coastal waters here are more suitable for nurturing broodstock, their larvae and the juvenile shrimps that can be sold on to farms. The hatcheries were also set up to supply the nearby intensive shrimp industry that was established in the 1980s. The capital-intensive industry was part of a so-called blue revolution, a key component, after garments, for export-led development of the Bangladeshi economy (Islam, 2014).

A disease called White Spot devastated most of the more intensively stocked farms in the area in the 1990s, leaving the hatcheries with a logistical and economic problem. The main market for PL was now located at the other end of the country and made up of a large number $(85,000)$ of predominantly small holder farms spread over an area of 143,000 hectares (figures derived from Belton et al. 2011, p. 25). Economically, the hatcheries not only faced an issue of potential over supply and depressed prices once the intensive farms had failed, they also faced transport costs, packaging and preservation challenges, and a market made up of small farmers whose ability to pay high prices for their seed was limited. As a result, economic margins (the relation between cash flow and capital invested) became tighter, and some of the hatcheries struggled to stay in business.

The 81 freshwater prawn (Macrobrachium rosenbergii) hatcheries, closer to the farmers in the southwest of Bangladesh, faced different problems. Most were currently struggling to produce at all, and technicians complained of disease and the failure of their tried and tested methods. A majority had given up and were not even attempting to produce in 2017 (the year we initially visited). For those that managed to produce a crop, the unit price at market would be high. But the high likelihood of failure meant that even potentially favourable economic margins were seldom enough to stay in business. Unless a hatchery had extraneous funds, for example from an aid organisation or NGO, or was cross-subsidised by another business (some hatchery owners have flourishing poultry operations), then disease challenges meant that much of the invested capital was likely to lie dormant. Mothballed capital is testimony to the (in this case failing) interrelations between an economic landscape of tight or uncertain margins and a world of biological margins (see Fig. 2). In crude terms we can define biological margins as a relation between throughput (in this case reproduction and survival of postlarvae to market) and the attempted adjustments to living processes in order to raise productivity. In the following we will describe some key critical points in this process.

Hatcheries operate by taking broodstock and inducing them to reproduce. The latter involves providing favourable spawning conditions and in some cases inflicting physical changes like eye stalk ablation in order to stimulate ovary development and/or increased egg production. The resulting eggs, and then larvae, are disinfected, cultivated and carefully nurtured through a series of life stages (nauplius, protozoea, mysis and postlarvae stages). Taking a largely solitary animal with a high reproduction to survival ratio and inducing enough seed to make the process economically viable is clearly far from straightforward. Temperature, water quality, aeration, light, feed and so on must be regulated throughout, and disease threats kept at bay.

In this process, hatcheries face a number of issues. First, there is a problem with broodstock. For all but one of the hatcheries in Bangladesh, broodstock is 'wild caught', purchased by hatchery technicians at port or market, having been fished in the Bay of Bengal (for tiger shrimp) or in rivers (for prawn). A common complaint in the hatcheries was that sourcing high quality broodstock was becoming increasingly difficult, with high prices and frequent disease problems. Iqbal et al. (2011) and Debnath et al. (2014) have confirmed disease prevalence in wild caught shrimp broodstock-reaching $90 \%$ occurrence of white spot syndrome virus (WSSV) in pre-Monsoon May-June catches. Market practices may contribute to this disease problem. Broodstock prices are normally set daily depending on catch size, and have not in the past allowed for differentiation in terms of origin (and by extension likely disease carriage). As a result there is little incentive for trawler crews to venture into deeper waters, where infection rates are likely to be lower, or indeed reduce disease risk through separating stock and managing animal stresses as they are landed and transported (Debnath et al. 2015).

Second, any attempt to test broodstock for disease and then secure tested individuals in disease-free conditions faces difficulties in terms of diagnostic capacity and tight economic margins. Polymerase Chain Reaction (PCR) testing for 12 registered production diseases is constrained by laboratory capacity (with a single independent NGO-and now Department of Fisheriesrun laboratory in Cox's Bazar). The costs associated with producing certified PL from these tested broodstock may also be difficult to implement. Hatcheries have been encouraged to adopt a 'one mother one tank' system as a means to reduce cross contamination, but the costs of doing so are only worthwhile if there is sufficient value added to the resulting certified product.

Third, even with sufficient testing, diseases and complications relating to environmental and microbiological challenges within the hatcheries are likely to remain a problem. There are emerging and re-emerging pathogens that will not be on the test-list. There are also diseases that relate to the interaction of several microorganisms and environmental stressors that will not be regarded as pathogens in isolation, but nevertheless may affect production. Shifts in environmental parameters can exert stresses on animals, increase susceptibility to disease and pose considerable challenges to production. For example, hatchery technicians reported increasingly frequent problems with input water quality. Elaborate systems of seawater filtration exist in many of the shrimp hatcheries but maintaining the conditions necessary for larval development is challenging when temperature, $\mathrm{pH}$, salinity, and other parameters can alter relatively quickly. For the prawn hatcheries, filtration systems are less developed, so technicians rely on sourcing good quality freshwater. The latter has become more difficult in recent years, and tankers must be sent further afield at added cost, a problem that is put down to rapid land use change, upstream damming, the vagaries of the monsoon and pollution.

Disease and antimicrobial use in hatcheries. The interrelationships between biological margins (a struggle to achieve reproduction and throughput) and economic margins (pinched as they are by supply imbalance and logistical costs, as well as marketing difficulties) result in an environment in which, despite private and public investments, antimicrobials continue to be an important disease management tool. Both shrimp and prawn hatcheries described a wide range of disease problems, and, significantly in our survey, all but one reported the regular and 


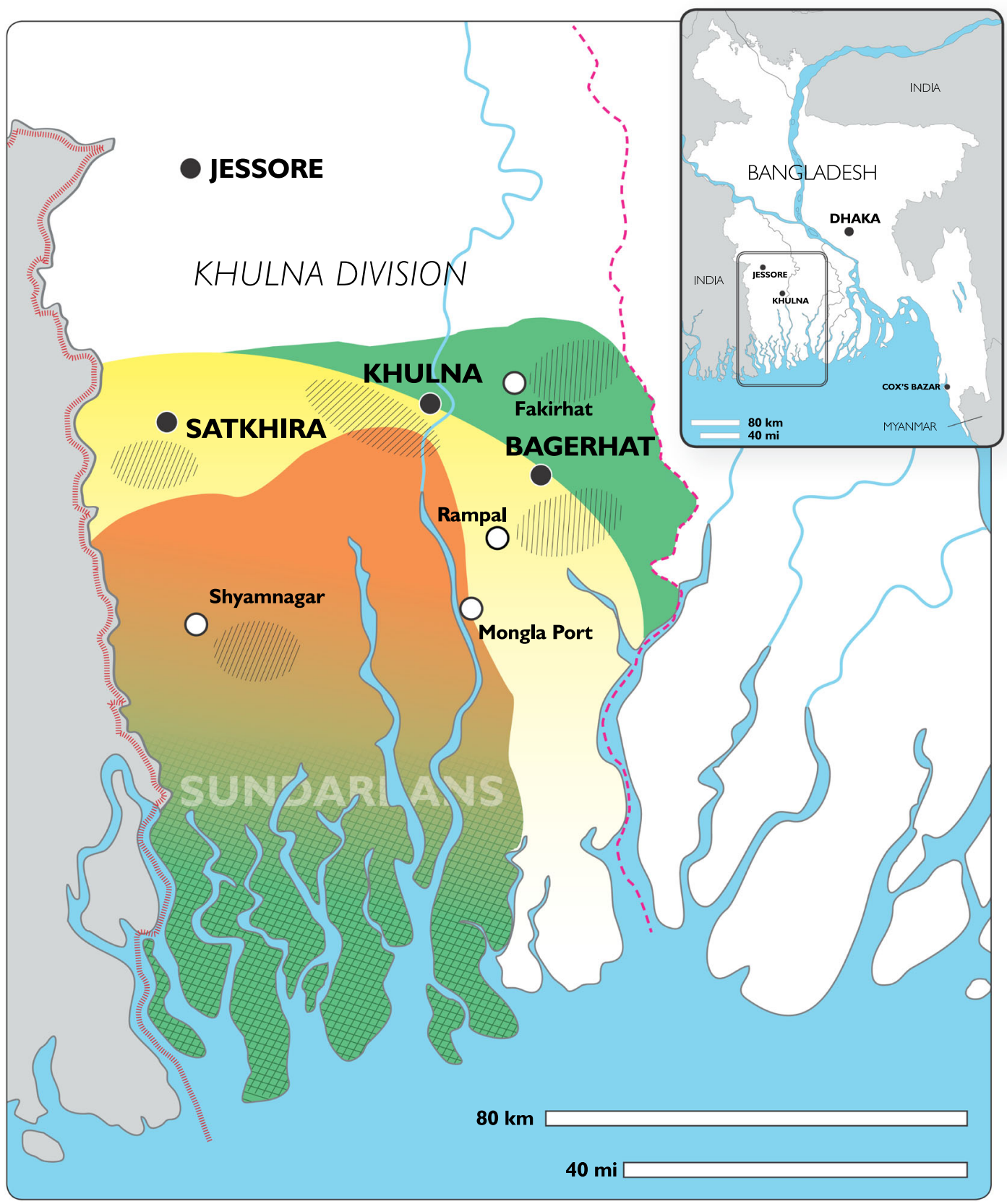

\section{LEGEND}
High salinity brackish water; shrimp dominant; no integrated agriculture
Medium Salinity brackish water; shrimp and prawn culture alternated with rice
Low salinity freshwater; prawn dominant; rice grown concurrently
Mangrove Forest
Areas in which survey farms were sampled
District capital

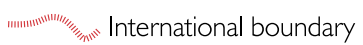
...-... Division boundary

Fig. 1 Map of SW Bangladesh, salinity conditions affect production types (with more saline areas cultivating shrimp, and fresher conditions prawn). Survey farms were located in the shaded areas

frequent use of antimicrobials. Usage included those compounds currently approved for aquaculture like Oxytetracycline-a broad-spectrum antibiotic-but also those that are on the WHO essential medicine list including Ciprofloxacin-a secondgeneration Fluoroquinolone that is inexpensive but associated with high levels of resistance-and Erythromycin. Hatchery technicians also stated that they continue to rely on treatments that have been banned since 2003 in food production including Furazolidone-a nitrofuran used to remove slime from PL but a known carcinogen-and Chloramphenicol-again a suspected 


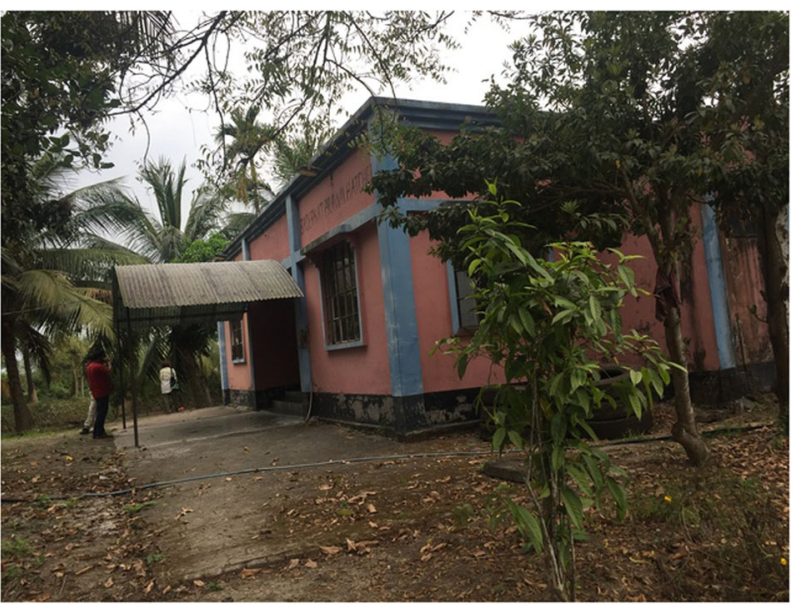

Fig. 2 A mothballed prawn hatchery in Bagerhat, SW Bangladesh

carcinogen and used by some hatcheries as a prophylactic or upon signs of necrosis (Jakiul Islam et al. 2014).

In all, 23 antimicrobial products were in use in hatcheries, with some reporting using $80 \mathrm{Kg}$ per production cycle. There are a number of reasons for this range of products. First, treatments were used for a variety of purposes. Some were applied to infected broodstock, some to treat live feed (artemia) for suspected Vibrio infections and others to treat developing larvae as they exhibited growth delay or other signs of disease. Second, technicians tended to adopt and use treatments on a trial and error basis, aiming to see a production cycle through to completion or rescuing a cohort from collapse once disease signs (like spiral swimming or lack of development) were observed. Formal diagnoses of disease prior to treatment were rare, and technicians relied on their experience, on advice from farm supply shops or from colleagues in other hatcheries (sometimes through formal and informal consortia, sometimes through tea meetings in supply shop front rooms) in order to match observed signs to disease and treatment. Third, technicians complained that the treatments themselves were often ineffective and therefore a range of products was needed. There were suspicions that many of the available products were substandard (and a risk that the more that they were discouraged from buying medicines through formal channels the more that there will be reliance on poorer quality sources). Technicians mentioned imports, adulteration and poor batch quality as potential problems. Moreover, few if any of the products had been devised with aquaculture in mind. They complained that medicines were initially devised for terrestrial animals or, at best, finfish, and re-packaged for the invertebrate market. Even standard products were therefore likely to behave imperfectly in the shrimp and prawn hatchery environment. Finally, there was talk of more frequent incidence of resistance, with technicians informally cycling treatments to reduce the likelihood of resistance or switching treatments once the animals failed to respond.

The point of this list is not to cast blame or sanction on hatcheries. Respondents in the hatcheries and supply shops were aware of regulations, the lack of effectiveness of these treatments and their possible drawbacks. For example, probiotic products have become popular in the shrimp hatcheries, but their effectiveness is reduced or even negated if antimicrobial products are used. There was also a suspicion that antibiotic applications can reduce growth and metamorphosis rates in the larval stages. Antimicrobial use was not therefore something that those working in hatcheries took lightly. Nevertheless, even after various interventions in terms of regulatory policy, biosecurity improvements, investment in water filtration and so on, the combined effects of poor quality broodstock, limited diagnostic capacity and persistent and frequent disease problems meant that most hatcheries continued to rely on antimicrobial treatments in order to produce viable PL. The pressure to deliver product at a certain price point meant that these treatments remained an essential if reluctantly applied crutch for the industry. As a result, there was potential dissemination of resistance conferring microbes to the tens of thousands of ponds that stock PL from these hatcheries.

One hatchery in Cox's Bazar stood out as using no antibiotics, producing SPF (specific pathogen free) PL. This hatchery, which has been in production for only a few years, used domestic tiger shrimp broodstock, bred from a stock-line imported from Hawaii. Producing PL from certified pathogen-free broodstock in carefully controlled conditions allowed this hatchery to market its PL differently, 'guaranteeing' it to be free from key production diseases. The selling price was high (up to 6 times the price of conventional, untested PL). At first blush this looks like an answer to some of the problems encountered elsewhere-a technical solution to the challenge of disease and reliance on antimicrobial treatments. But to understand the remaining challenges we need to shift site and move to the farms where the PL, after a journey of anything from 14 hours to several days, is added to grow-out ponds.

\section{Farming on the margins}

There is normally money to be made in shrimp and prawn farming. In the last few decades it has been a high value product, one that relatively few people in rural Bangladesh can afford to purchase, but one that has tended to generate sizable foreign exchange and a valuable cash crop. In 2016-17, Bangladesh exported 40,000 $\mathrm{mt}$ of high value shellfish (shrimp and prawn) earning US $\$ 450 \mathrm{M}$ in export earnings-though these figures were closer to $48,000 \mathrm{mt}$ and US\$550 M in 2013-14 (Bangladesh Department of Fisheries, 2017). The estimated 180,000 shrimp and prawn farms sell their produce to depots and/ or wholesalers at market, or to faria (market intermediaries who link farms to supplies and sales). Depots then sell to processing factories, many of which are operating well below capacity. The market process is close to what Tsing (2015, p. 63) describes as "salvage accumulation", where lead firms (in this case processors) "amass capital without controlling the conditions under which commodities are produced." The importance of this "pericapitalist" process is that farms are simultaneously both inside and outside what is conventionally called capitalism. For example, ponds are to some extent outside conventional schemes of formal regulation and accountability. They constitute part of what Kakkar et al. (2018) refer to as the "invisible cohorts" of backyard and smallholder farms producing $70 \%$ of the world's food. The style of pond, the management processes adopted, the treatments used, the ways in which aquaculture is combined with other livelihood activities all make for a highly variable landscape of production, while the system of sales and collection renders individual farms as largely invisible to processors and retailers. Even so, the ponds are subject to market pressures and international competition. The latter has grown in the last few years largely as a result of expansion in Pacific whiteleg shrimp (Litopenaeus vannamei) aquaculture in other Asian countries. L. vannemei, which is not currently sanctioned for introduction into Bangladesh, has proved attractive to producers elsewhere owing to its relative disease resistance, the availability of SPF broodstock and ease of culture. The competition has left Bangladeshi farmers with an issue-as increased global production and falling prices are communicated along the intricate supply chain, farmers are 


Table 1 Definitions of aquaculture management practices (Source: Jahan et al. 2015, p. 23) NB we have adopted the term
improved extensive rather than semi-intensive in order to mirror the terms used in the field and reflect practice in shrimp and
prawn cultivation

starting to find it more and more difficult to make a profit from their ponds.

Almost all ponds that culture shrimp and/ or prawn in Bangladesh can be classed as extensive or improved extensive using the scheme in Table 1. Most use flooded rice fields (called gher) to culture tiger shrimp and/or prawn in open systems (see Fig. 3). In our survey, ponds varied in size, ranging from small homestead ponds of around 0.1 ha (or roughly 10 by $10 \mathrm{~m}$ ) to the larger gher in the more saline districts (which tend to be 1 ha in size but can be much larger). Ponds tended to be relatively shallow (around $1 \mathrm{~m}-1.50 \mathrm{~m}$ depth), often with a canal or ditch (for water storage) and may be used for a variety of food growing purposes (with salt-resistant aman and boro paddy rice polyculture a common feature).

These extensive and improved extensive, open system, farms are arguably more susceptible to disease transmission than closed system alternatives. In our sample of 320 farms, $84 \%$ reported production diseases, and average mortality (the ratio of $\mathrm{PL}$ introduced to the system to the numbers harvested) for the sampled farms was calculated at $82 \%$ for shrimp and $62 \%$ for prawn. Key aims for the sector include improving productivity and produce quality, reducing the burden of disease and so minimising antimicrobial uses in an increasingly competitive global market. Favoured Department of Fisheries and NGO-led interventions include encouraging farmers to use high quality, preferably SPF, PL from the hatcheries (in order to reduce the risk of introduced disease) (Rahman et al. 2018). In the previous section we discussed the difficulties associated with producing quality seed. We now discuss the difficulties and possible paradoxes of implementing these changes on farms.

Seed, feed, and risk. Tested and SPF seed on farms promises reduced disease risk, increased food security, and improved rural livelihoods, all without the requirement for unsustainable use of antimicrobial or other treatments. However, just as there are difficulties associated with producing the required seed, there is a need to understand the biosocial situations of farmers and ponds in order to appreciate the nature of the AMR challenge.

Disease was a common issue for most farmers, with nearly $85 \%$ of farmers reporting a range of diseases in shrimp and prawn in

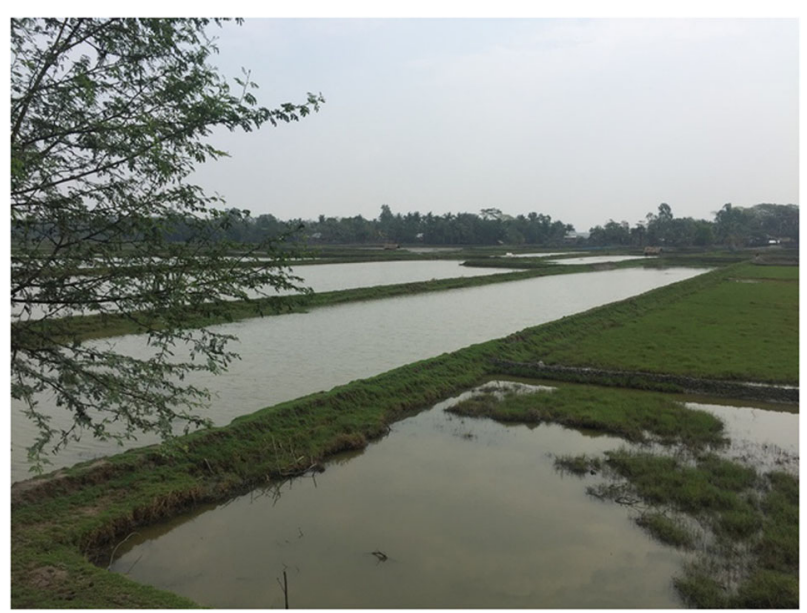

Fig. 3 Typical 'ghers' in SW Bangladesh - flooded and embanked rice fields used for the cultivation of shrimp

2017. In contrast to the hatcheries, and despite the high value of the crop, farmers reported very low and in the majority of cases no antibiotic use in their ponds. This may be an artefact of response bias, and in part a reflection of some degree of uncertainty about what various treatments contained. However, low to zero use is consistent with other research (Rico et al. 2013, Ali et al. 2016), with our interviews with supply shop owners and more broadly with the experience of the wider research team in Bangladesh. Antibiotics are certainly freely available, and a viable option for some of the smaller ponds, but at present their use tends to be only as a last resort. As we stated earlier, even small quantities of antibiotics may be significant in terms of resistance risk, but for most farms resistance issues are more probably linked to drivers other than on farm antibiotic use.

On the farms, adapting to disease and disease risks involved two main strategies. First, farmers used their pond and surrounding banks to culture other crops. Spreading risk through polyculture has been encouraged by NGOs and the Ministry for 
Fisheries in Bangladesh as beneficial for both rural livelihoods and for environmental sustainability. Concurrent or alternate crops of paddy rice and the culturing of various finfish help to provide income and nutrition should the shrimp or prawn crop fail. Almost all of the ponds we visited and surveyed cultivated more than one crop. The effect in terms of productivity can be impressive. For example, finfish production raised the productivity of ponds from an average of $200-300 \mathrm{KgHa}^{-1}$ for shrimp and or prawn, to over $1100 \mathrm{KgHa}^{-1}$ once finfish were taken into account.

Second, farmers have developed practical production methods in a system where disease is common. Most of the farms we surveyed (89\%) practised multi-stocking, adding PL to a pond at regular intervals throughout the stocking season (from February to August), as frequently as every two weeks, over several months. On the face of it, this is a risky practice, increasing the probability that diseases will be introduced to the pond through contaminated PL and or pond equipment. In comparison, single stocking 'all in all out' practice would reduce disease transmission risks, allow farmers to optimise stocking densities, improve pond sediment and water management (disinfecting between stocking events) and reduce the incidence of cannibalistic predation (older shrimp and prawn tend to feed on juveniles). Yet, despite these extra risks, multi-stocking provides a number of advantages for farmers. In terms of farm finances, it spreads costs and income over longer periods. PL purchase was the largest single running cost for a farm, accounting for on average $45 \%$ of farmers' total costs. Regularly buying small amounts of seed enabled farmers to manage their outgoings but also take advantage of falling prices once the key periods of demand and short supply had passed. The result was a reduced reliance on credit (or dadon, where farmers effectively pledge a portion of their harvest in exchange for seed). As others have shown, the credit system in Bangladesh whereby farmers enter into debt bondage effectively results in farmers bearing the greatest production risks (Barmon et al. 2011). Avoiding debt by spreading costs may be a key means to reduce those risks. Regular stocking also allowed farmers to generate income over a longer period and take advantage of any seasonal changes in market prices.

Multi-stocking can also, and at first sight paradoxically, make disease risk more manageable. An 'all in all out' system clearly has advantages in terms of biosecurity, but it comes with increased financial exposure to disease risk when the sum total of a farmer's investment can be lost in a single disease event. Multistocking means that farmers could gradually manage the pond stock and adjust stocking depending on the health status of the ponds. During our fieldwork (2017-2018), farmers spoke of a previously unknown disease or syndrome that tended to affect shrimp just before they reached harvest weight (between 20-35 g). This disease was of particular concern because several months' feed and labour were effectively embodied in the affected stock. If all the stock was derived from one stocking event then it is easy to see how farmers can see this is as a catastrophic risk. Multi-stocking may not change this outcome, but, given the rapid changes that can occur in pond conditions (changing salinity, $\mathrm{pH}$, depth and so on, particularly after the onset of the monsoon), a staggered approach to stocking may increase the chances of producing some kind of harvest. In contrast, a single stocked pond can drive treatment decisions. If the farmer risks losing all their income in a single disease event then they may be more likely to use antimicrobial treatments. When economic and biological margins are at the limit, and a salvage accumulation supply chain militates against traceability, farmers may feel that there is little choice but to attempt to rescue their cash crop through use of antimicrobial or other available treatments.
Finally, multi-stocking is also driven by an undersupply of certified seed and farmers' experience of the relative differences between hatchery conditions and those of the ponds. When we asked farmers about their preferred source of PL (for example whether they preferred the SPF variety or, as some reported, they preferred to use wild caught PL or were happy with untested), the response was generally that, in practice, they tended to buy what was available and affordable. Even when farmers managed to procure tested or disease-free seed, the presence of other seed, finfish stocks (often from wild seed or catches), the conditions of the pond, its salinity, temperature, $\mathrm{pH}$, microbiome, and so on were likely to depart significantly from hatchery conditions and the transport medium (shrimp PL are transported in units of 1000 , in a saline medium in plastic bags). Most PL are introduced straight into ponds with no acclimatisation, and the sudden change in environmental parameters can affect morbidity and mortality. Farmers complained that hatchery PL was often weak after transportation. The resulting high mortality meant that restocking became necessary once the survival rate had been gauged by the farmer.

Clearly, seed quality is but one, albeit important, contributor to disease risk. The ways in which farmers managed their ponds in light of seed supply problems and through their adjustments of risks may well offset any promised gains in productivity. As tested and SPF seed can cost up to 6 times the lowest prices for untested PL and with wild seed often preferred for its relative resilience, the rationale for switching to higher end seed was less than clear to some farmers. In adaptive change terms, it is evident that any technical adjustments to seed quality (testing and SPF) need to consider the ways in which farmers secure livelihood from their farms. In the final section, we outline a process through which farmers and other relevant experts were involved in a process of re-framing the issues and developing ways of meeting these adaptive challenges.

\section{Challenging the disease and AMR model: competency groups and AMR}

One approach to managing disease and AMR risks is to seek to alter farmer behaviour in order that it conforms to a pre-existing model (reducing disease transmission risks as a means to lower future demand for antimicrobial treatments). From what we have said so far, this might profitably involve changing farm practices and educating farmers on the risks of inappropriate antibiotic use. The difficulty from the perspective of compliance with technical changes is that some of these practices are strongly embedded in social ecologies of food production, in what we have characterised as a form of pericapitalist salvage accumulation where farming practices are adapted to frequent disease challenges.

An alternative approach is to work together with farmers and other relevant spokespeople, using collective expertise and experience, in order to generate greater understanding of on farm practices and processes, resulting disease and AMR risks and to identify possible pathways to change. To build on the interview and survey materials generated in the project, we hosted workshops, where farmers were invited alongside others in the sector (supply shop owners, exporters, government officials from the Department of Fisheries) to produce a model of pond processes, including disease and AMR drivers. We ran a process where around 40 farmers, of mixed gender, age, location and background (including some finfish farmers) joined other participants to constitute a competency group (Whatmore, 2009), initially working in smaller mixed groups over 2 days, to populate diagrams with key inputs and conditions that made their ponds work. They followed this by superimposing pathways and stressors that they associated with disease risks (like for example the 
addition of infected PL, or sudden changes in water depth). Groups then discussed and annotated the emerging diagrams with potential drivers of AMR (including antimicrobial uses, but also commercial and locally produced feed, pesticides and pollution) and its transmission. A composite model of 10 groups' work was generated and discussed by participants in order to make sure it represented their discussions Figs. 4-6.

The result was, predictably, a complex picture of numerous material flows and pressures (from temperature and salinity fluctuations to the role of banks and credit) (Fig. 6). Some parsimony for the emerging 'model' was attempted in terms of participants ranking key processes (and a later stage, not reported here, whereby survey data was used to corroborate key relations) -but the objective here was not the development of a formal process model in what is a heterogeneous and open system. Instead the competency groups generated new questions and issues that required interrogation and testing. In Leach and Scoones' (2013, p. 11) terms, participatory modelling draws "attention to the importance of diverse forms of knowledge and perspective" that are sometimes lost from conventional modelling approaches. It is these other knowledges that we draw out here.

Two examples allow us to illustrate the issues, the first relates to disease management and the second to AMR. First, we are used to the idea that disease is a multifactorial issue, an interrelation of pathogen, host and environment that is modulated by social situations (Farmer, 2004, Hinchliffe et al. 2016). Likewise, the interaction of an assemblage of microbes can it seems 'tip' a relatively healthy microbiome into a 'pathobiome', an assemblage of microorganisms and physical pond parameters interacting to produce disease outbreaks (Vayssier-Taussat et al. 2014, Stentiford et al. 2017). We have already suggested that many farmers were implicitly aware of this openness and lack of determinacy, in ways that may explain some reluctance to change the way they face disease risks. Moreover, in highlighting the roles of the availability of money, lack of profit and supply chain arrangements on farmer practices and choices, the groups effectively raised social drivers of risk and disease. Groups could therefore start to explore how the alteration of a risk profile through access to affordable finance would in turn modulate the pond's pathobiome. In other words, we could start to talk sensibly of the sociobiome, which we can define as the assemblage of accumulation and other activities that interact to produce or modulate pond health.

Second, the participatory modellers' expansive diagrams of pond processes opened up the breadth of potential AMR risks. While this mirrors the scientific literature on the multiple drivers of resistance (see earlier), it is generated from a different knowledge base - one rooted in an appreciation of the social and ecological processes that condition a pond. As farmers described their ponds in relation to flows of materials, environmental relations, and stressors, a range of possible sources of antimicrobial compounds became apparent. Competency groups highlighted the use of antimicrobials in hatcheries as a possible source of resistant bacteria. They suspected feeds, particularly commercial pellets, contained antimicrobial compounds. Farmers complained that feed was often of poor quality and would quickly degrade in the hot and humid environment. Companies were increasingly claiming longer shelf-life and enhanced results from using their feeds, something that was likely to signal the off-label addition of antimicrobial compounds into the feed. Some talked of the hard-sell applied by commercial feed and pharmaceutical companies who were keen to push products, including antimicrobials, at farmers and supply shops. Other 'organic' feeds were also thought likely to pose AMR risks. Waste from poultry farms, where antibiotics are used in large quantities, were used to fertilise ponds. The role of detergents and pesticides as potential

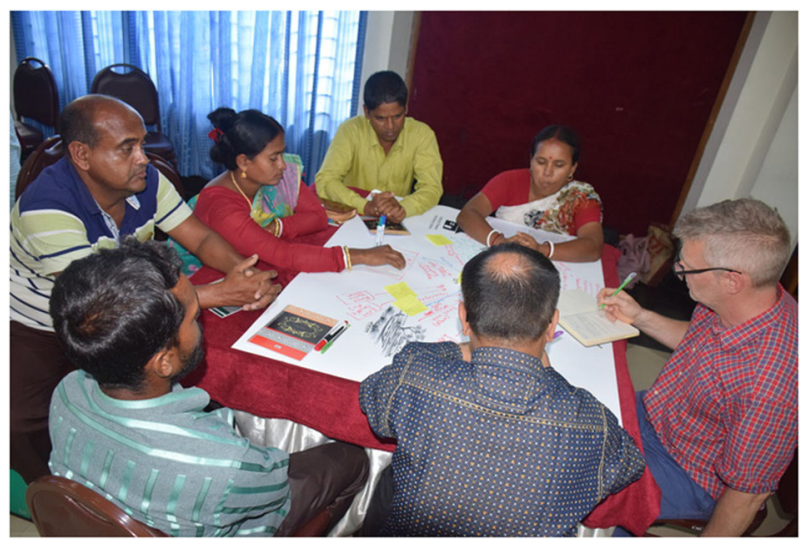

Fig. 4 Farmer group mapping out the components of a pond system

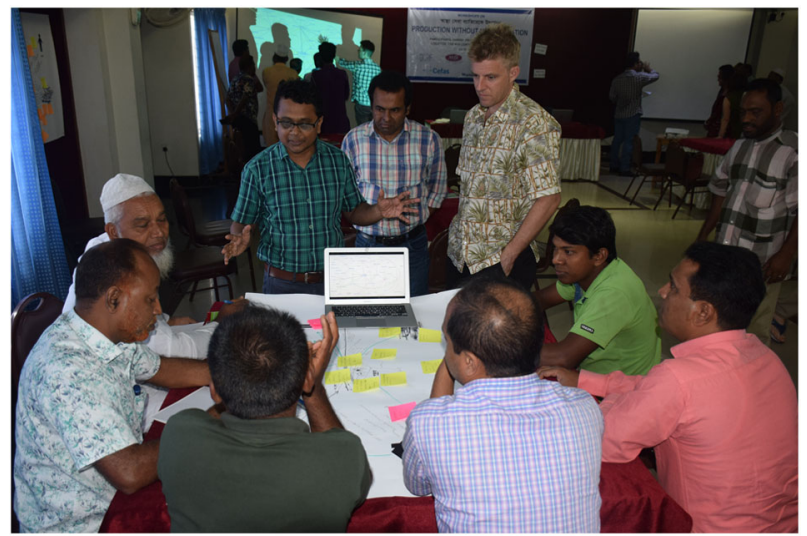

Fig. 5 Group discussing the composite model

contributors to resistance were also included in the participatory exercises. Finally, the models highlighted the openness of ponds, with inundation (during monsoon and cyclones), as well as outflow from neighbouring farms, from hospitals and both agricultural and industrial land uses, likely to affect the pathways and potentials of resistance conferring materials.

This appreciation of the openness of ponds to a variety of influences was an important conditioner of farmers' willingness or capacity to adopt technical changes, especially when these involved added costs or made risks less manageable. Farmers were well aware that good seed and good feed would improve their chances of making a profit in an increasingly difficult market. But they also knew that there was no easy fix to disease and resistance risks. If disease did not enter the pond through PL then it would just as likely transmit via predators or emerge as water temperature and salinity fluctuated in the lead up to and following the monsoon. Open systems were open to disease. Similarly, resistance risks could relate to the broader environment and to the operations of feed and farm supply companies.

A final point was that as farmers started to speak, often passionately, about their land, their ponds and the role they have played in Bangladesh's recent history, a different logic emerged from these diagrams. Diagrams shifted from being solely a representation of the multiple hazards that farms faced, to signifying interconnectivity and the strength that came from working with rather than against the landscape. Farmers communicated an attachment to homestead, to farming, to the broader landscape, and an ability to work with the multifaceted aspects of farming in Bangladesh. There was pride in both contributing to Bangladesh's recent economic successes and in 


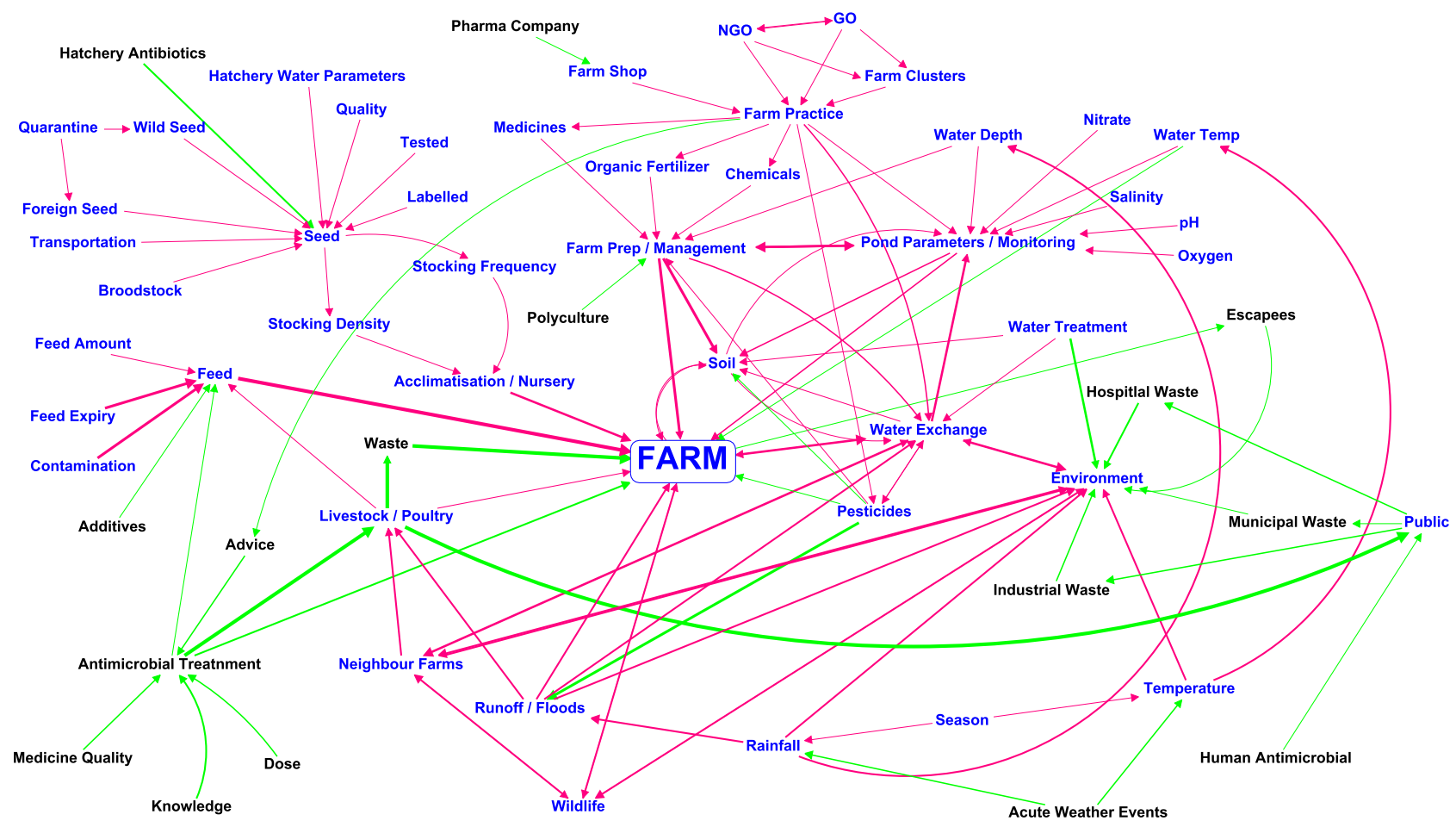

Fig. 6 The aquaculture pond system output - an open system with multiple pathways and drivers of disease and resistance risk

making farming a success in a challenging environment. Some spoke of the need to maintain the rich ecology of Bangladesh and to farm in ways that met the needs of the population at the same time as protecting their landscape.

\section{Conclusions}

So what to do with a problem like AMR? Our general, as well as specific answer is that a form of stewardship rooted in a reductionist or 'lite', as well as first world model of social science can prove ineffective in addressing the drivers and pressures that shape the emergence, persistence and transmission of resistance. So, instead of limiting social science to individualised or behavioural interventions, it is necessary to embed all actors, from microbes to people, to markets, within their webs of associations. Once we re-embed hatcheries, ponds, shrimp, farmers, resistomes and pathobiomes in their social ecologies of food production, in salvage accumulation supply chains, in managing risk profiles and economic, as well as biological margins, then the AMR problem is re-framed. In hatcheries, we detailed how, despite the efforts of technicians and others, economic and biological margins result in a continuing reliance on antimicrobials. Where investment is made to reduce this need, the issue becomes the extent to which disease-free seed can be translated to what Kakkar et al. (2018) refer to as an 'invisible cohorts' of pericapitalist small-holders and farmers.

On the farms, we demonstrated how attempts to secure production without medicalization by improving seed and biosecurity requires an appreciation of how farmers operate and manage in the face frequent disease events. Multi-stocking may contribute to high incidence of disease and poor overall productivity figures. Yet these practices also allow farmers to reduce their exposure to risk of failure. In this sense it may offer the best practicable means of securing an income and reducing the need for antimicrobial treatments. Higher biosecurity associated with single stocking may, paradoxically, increase the pressure to use more treatments. Clearly, better quality seed is to be welcomed, but for the majority of small farmers in Bangladesh, it needs to be made available across the production period at affordable prices in order that any benefits are not masked or undone as farmers top up stock with lower quality PL.

In developing competency groups and working with farmers to model their farms we highlighted the openness and multifaceted nature of farming, diagramming an array of resistance and disease risks. This appreciation of the multifaceted nature of disease and AMR, and the strategies for farming within that social ecology, underlined the importance of working with, rather than ignoring, farmer experience and expertise (Hinchliffe et al. 2018). Disease management would clearly need to incorporate the expertise and management practices of farmers, while investigations of resistance risks would need to range beyond current antimicrobial uses. The suspicion that commercial, as well as organic feed and fertiliser inputs, pollution, and other elements of the aqueous environment might drive the emergence, transmission and persistence of resistance would require further investigation.

An alternative to an eviscerated or disembedded understanding of social and economic practice is to encourage those with experience and expertise to articulate the issues. This is what we would understand by the significance of engagement and ownership (World Health Organisation, 2005), locally generated evidence (Wellcome Trust, 2016) and a situated analysis of disease, as well as drivers of AMR risks (Hinchliffe et al. 2016, Kakkar et al. 2018). In re-framing the AMR problem, it becomes incumbent on social scientists to develop approaches that allow us to appreciate how 'the social' gets under the skin, into the water, into cells, and formats a resistome or microbiome. Once we have grasped the interrelations between markets, accumulation and the strategies that people, animals and microbes have for living within those conditions, we can start to assess the potential of strategies for reducing the AMR risks in a sustainable fashion. This will involve a clearer understanding of the ways in which antimicrobials become embedded within particular 
configurations or social ecologies of food production. So, a pursuit of pathogen-free farming, for example, may paradoxically generate the socio-economic conditions for more rather than less antibiotics by altering the ways in which farmers face disease risks. An approach that foregrounds the multifactorial drivers of disease and resistance, the pathobiome and the sociobiome in our terms, involves generating meaningful competency groupings, developing ownership of the issue and a collective specification of where the real gains are to be had. By re-framing the AMR issue as an adaptive challenge, there is an opportunity to question approaches that continue anti-biosis by other means, and instead foster the different kinds of relationships that people have with their microbial and wider environments. Rather than see microbial surplus as a weakness, and without wanting to romanticise or underplay the costs of diseases, improved food production is predicated on these microbial relations.

Received: 14 August 2018 Accepted: 7 November 2018 Published online: 27 November 2018

\section{References}

Ali H, Rico A, Murshed-e-Jahan K, Belton B (2016) An assessment of chemical and biological product use in aquaculture in Bangladesh. Aquaculture 454:199-209

Bangladesh Department of Fisheries (2017) Yearbook of fisheries statistics of Bangladesh 2016-17. Vol. 34, Director General, DoF, 2017, Fisheries Resources Survey System (FRSS), Department of Fisheries, Bangladesh

Barmon BK, Chaudhury M, Munim SS (2011) Value chain and marketing channels of shrimp/prawn sector of gher farming system in Bangladesh. World Rev Bus Res 1(1):10-24

Belton B, Manjurul K, Shakuntala T, Murshed-E-Jahan K, Collis W, Phillips M (2011) Review of aquaculture and fish consumption in Bangladesh. Studies and Reviews 2011-53. Penang, World Fish Centre, Penang

Bengtsson-Palme J, Kristiansson E, Larsson DGJ (2018) Environmental factors influencing the development and spread of antibiotic resistance. FEMS Microbiol Rev 42(1):fux053-fux053

Bottery MJ, Wood AJ, Brockhurst MA (2016) Selective conditions for a multidrug resistance plasmid depend on the sociality of antibiotic resistance. Antimicrob Agents Chemother 60(4):2524-2527

Cabello FC, Godfrey HP, Buschmann AH, Dolz HJ (2016) Aquaculture as yet another environmental gateway to the development and globalisation of antimicrobial resistance. Lancet Infect 16(July 2016):127-133

Callon M (1986) Some elements of a sociology of translation: domestication of the scallops and the fishermen of St Brieuc Bay. Power, action and belief. Jouranl of Law, London, Routledge and Kegan Paul p. 196-223

Davies SC (2013) The drugs don't work: a global threat. Penguin, London

Debnath P, Karim M, Belton B (2014) Comparative study of the reproductive performance and White Spot Syndrome Virus (WSSV) status of black tiger shrimp (Penaeus monodon) collected from the Bay of Bengal. Aquaculture 424-5:71-77

Debnath P, Khan SH, Karim M, Belton B, Mohan Vishnumurthy C, Phillips M (2015) Review of the history, status and prospects of the black tiger shrimp (Penaeus monodon) hatchery sector in Bangladesh. Rev Aquac 8(3):301-313

FAO (2018) The State of World Fisheries and Aquaculture 2018-Meeting the sustainable development goals. Licence: CC BY-NC-SA3.0 IGO. Rome

Farmer P (2004) Pathologies of power. University of California Press, Berkeley

Farmer P, Nizeye B, Stulac S, Keshavjee S (2006) Structural violence and clinical medicine. PLoS Med 3(10):e449. https://doi.org/410.1371/journal.pmed.0030449

Gillings MR (2017) Lateral gene transfer, bacterial genome evolution, and the Anthropocene. Ann N Y Acad Sci 1389:20-39

Heifetz RA (1994) Leadership without easy answers. Harvard University Press, Cambridge, Mass

Hinchliffe S, Bingham N, Allen J, Carter S (2016) Pathological lives: disease. In: Space and Biopolitics. Wiley Blackwell, London UK

Hinchliffe S, Jackson MA, Wyatt K, Barlow AE, Barreto M, Clare L, Depledge MH, Durie R, Fleming LE, Groom N, Morrissey K, Salisbury L, Thomas F (2018) Healthy publics: enabling cultures and environments for health. Palgrave Commun 4(1):57

Holmes AH, Moore LSP, Sundsfjord A, Steinbakk M, Regmi S, Karkey A, Guerin PJ, Piddock LJV (2016) Understanding the mechanisms and drivers of antimicrobial resistance. Lancet 387(10014):176-187
Iqbal MM, Kabir MA, Alan CB, Mamun MAA, Hossain MM (2011) Seasonal status of white spot syndrome virus in broodstocks, nauplii and postlarvae of black tiger shrimp (Penaeus monodon) in Bangladesh. Int J Nat Sci 1 (3):56-61

Islam MS (2014) Confronting the blue revolution: industrial aquaculture and sustainability in the global south. University of Toronto Press, Toronto

Jahan K, Belton B, Ali H, Dhar GS, Ara I (2015) Aquaculture technologies in Bangladesh: an assessment of technical and economic performance and producer behavior. Penang, Malaysia, WorldFish. Program Report: 2015-52

Jakiul Islam M, Liza AA, Reza A, Reza MS, Khan M, Kamal M (2014) Source identification and entry pathways of banned antibiotics nitrofuran and chloramphenicol in shrimp value chain of Bangladesh. Eurasia J Biosci 8:71-83

Jalais A (2011) Forest of tigers: people, politics and environment in the sunderbarns. Routledge, London

Kakkar M, Chatterjee P, Singh Chauhan A, Grace D, Lindahl J, Beeche A, Fang J, Chotinan S (2018) Antimicrobial Resistance in South East Asia: Time to ask the right questions. Glob Health Action 11(1):1483637

Landecker H (2016) Antibiotic resistance and the biology of history. Body Soc 22 (4):19-52

Law J (2004) After method: mess in social science research. Routledge, London

Law J (2006) Traduction/trahison: notes on ANT. Convergencia 42:47-72

Law J, Hassard J (eds) (1999) Actor network theory and after. Blackwell and Sociological Review, Oxford and Keele

Laxminarayan R, Duse A, Wattal C, Zaidi AKM, Wertheim HFL, Sumpradit N, Vlieghe E, Hara GL, Gould IM, Goossens H, Greko C, So AD, Bigdeli M, Tomson G, Woodhouse W, Ombaka E, Peralta AQ, Qamar FN, Mir F, Kariuki S, Bhutta ZA, Coates A, Bergstrom R, Wright GD, Brown ED, Cars O (2013) Antibiotic resistance-the need for global solutions. Lancet Infect Dis 13(12):1057-1098

Leach M, Scoones I (2013) The social and political lives of zoonotic disease models: narratives, science and policy. Social Sci Med 88:10-17

Lee N, Motzkau J (2013) Varieities of biosocial imagination: reframing responses to climate change and antibiotic resistance. Sci Technol Human Values 38 (4):447-469

Leung E, Weil D, Raviglione M, Nakatani H (2011) The WHO policy package to combat antimicrobial resistance. Bulletin of the World Health Organisation. WHO, Geneva, Switzerland, p 390-392

Marcus GE (1995) Ethnography in/of the world system: the emergence of multisited ethnography. Annu Rev Anthropol 24:95-117

Rahman MM, Keus HJ, Debnath P, Shahrier MB, Sarwer RH, Kudrat-E-Kabir QAZM, Mohan CV (2018) Benefits of stocking white spot syndrome virus infection free shrimp (Penaeus monodon) post larvae in extensive ghers of Bangladesh. Aquaculture 486:210-216

Rico A, Phu TM, Satapornvanit K, Min J, Shahabuddin AM, Henriksson PJG Murray FJ, Little DC, Dalsgaard A, Van den Brink PJ (2013) Use of veterinary medicines, feed additives and probiotics in four majorinternationally traded aquaculture species farmed in Asia. Aquaculture 412-13:231-243

Stentiford G, Sritunyalucksana K, Flegel T, Williams B, Withyachumnarnkul B, Itsathitphaisarn O, Bass D (2017) New paradigms to help solve the global aquaculture disease crisis. PLoS Pathog 13(2):e1006160. https://doi.org/ 1006110.1001371/journal.ppat.1006160

Taylor NGH, Verner-Jeffreys DW, Baker-Austin C (2011) Aquatic systems: maintaining, mixing and mobilising antimicrobial resistance? Trends Ecol Evol 26(6):278-284

Tsing AL (2015) The mushroom at the end of the world. Princeton University Press, Princeton and Oxford

Van Boeckel TP, Brower C, Gilbert M, Grenfell BT, Levin SA, Robinson TP, Teillant A, Laxminarayan R (2015) Global trends in antimicrobial use in food animals. Proc Natl Acad Sci 112(18):5649-5654

Van Boeckel TP, Gandra S, Ashok A, Caudron Q, Grenfell BT, Levin SA, Laxminarayan R (2014) Global antibiotic consumption 2000 to 2010: an analysis of national pharmaceutical sales data. Lancet Infect Dis 14(8):742-750

Vayssier-Taussat M, Albina E, Citti C, Cosson J-F, Jacques M-A, Lebrun M-H, Le Loir Y, Ogliastro M, Petit M-A, Roumagnac P, Candresse T (2014) Shifting the paradigm from pathogens to pathobiome: new concepts in the light of meta-omics. Front Cell Infect Microbiol 4:29-29

Wellcome Trust (2016) Integrating science and policy for decisive action on antimicrobial resistance. Evidence for antimicrobial resistance 2. Wellcome Trust, London

Whatmore S (2009) Mapping knowledge controversies: science, democracy and the redistribution of expertise. Progress Human Geogr 33(5):587-598

Whatmore S, Landstrom C (2011) Flood apprentices: an exercise in making things public. Econ Soc 40(4):582-610

Wistrand-Yuen E, Knopp M, Hjort K, Koskiniemi S, Berg OG, Andersson DI (2018) Evolution of high-level resistance during low-level antibiotic exposure. Nat Commun 9(1):1599 
World Health Organisation (2005) Policy perspectives on medicines No.10: containing antimicrobial resistance. Geneva, Switzerland

World Health Organisation (2015) Global Action Plan on AMR. Geneva, Switzerland

\section{Data availability}

The datasets generated during the study are being prepared for deposit at the end of the project and are not currently publicly available. They are available from the corresponding author on reasonable request.

\section{Acknowledgements}

The research was funded by the ESRC under the cross UK Research Council "Tacking Antimicrobial Resistance" programme-grant number ES/P004008/1 (Production without medicalisation: a pilot intervention in global protein production). Colleagues at CEFAS in the UK (David Verner-Jeffreys, James Guilder and Hannah Tidbury), at Arban in Bangladesh (Syed Arifuzzaman) and Charles Tyler (Biosciences, University of Exeter) all helped to develop the project.

\section{Additional information}

Competing interests: The authors declare no competing interests.
Reprints and permission information is available online at http://www.nature.com/ reprints

Publisher's note: Springer Nature remains neutral with regard to jurisdictional claims in published maps and institutional affiliations.

\section{(c) (1)}

Open Access This article is licensed under a Creative Commons Attribution 4.0 International License, which permits use, sharing, adaptation, distribution and reproduction in any medium or format, as long as you give appropriate credit to the original author(s) and the source, provide a link to the Creative Commons license, and indicate if changes were made. The images or other third party material in this article are included in the article's Creative Commons license, unless indicated otherwise in a credit line to the material. If material is not included in the article's Creative Commons license and your intended use is not permitted by statutory regulation or exceeds the permitted use, you will need to obtain permission directly from the copyright holder. To view a copy of this license, visit http://creativecommons.org/ licenses/by/4.0/.

() The Author(s) 2018 